OPEN ACCESS

Edited by:

Yuka Kotozaki,

Iwate Medical University, Japan

Reviewed by:

William Lodge,

Brown University, United States

Jean Lillian Paul,

Medizinische Universität

Innsbruck, Austria

Segundo Ramos Leon,

San Juan Bautista Private

University, Peru

*Correspondence:

Sergio Bautista-Arredondo sbautista@insp.mx

Specialty section:

This article was submitted to

Public Mental Health,

a section of the journal

Frontiers in Public Health

Received: 25 August 2020 Accepted: 06 April 2021

Published: 07 June 2021

Citation:

Cerecero-Garcia D, Vermandere $H$,

Bojorquez I, Gómez-Castro J, Arturo

Sánchez-Ochoa J,

Martínez-Dávalos A, Huerta-Icelo I and

Bautista-Arredondo S (2021) Profiles

of Depressive Symptoms Among Men

Who Have Sex With Men and

Transgender Women During the

COVID-19 Outbreak in Mexico: A

Latent Class Analysis.

Front. Public Health 9:598921.

doi: 10.3389/fpubh.2021.598921

\section{Profiles of Depressive Symptoms Among Men Who Have Sex With Men and Transgender Women During the COVID-19 Outbreak in Mexico: A Latent Class Analysis}

\author{
Diego Cerecero-Garcia ${ }^{1}$, Heleen Vermandere ${ }^{1}$, letza Bojorquez², José Gómez-Castro ${ }^{1}$, \\ José Arturo Sánchez-Ochoa ${ }^{1}$, Araczy Martínez-Dávalos ${ }^{1}$, Ivonne Huerta-Icelo ${ }^{1}$ and \\ Sergio Bautista-Arredondo ${ }^{1 *}$ \\ ${ }^{1}$ Center for Health Systems Research, National Institute of Public Health, Cuernavaca, Mexico, ${ }^{2}$ Department of Population \\ Studies, El Colegio de la Frontera Norte, Tijuana, Mexico
}

The impact of the COVID-19 outbreak on mental health among HIV high-risk populations is not known. We assess the prevalence of depressive symptoms (DS) and explore the association with characteristics related to the COVID-19 pandemic. We conducted an online survey among 881 men who have sex with men (MSM) and transgender women (TGW) assessing the presence of DS using the Center for Epidemiological Studies Depression Scale (CESD-10); results were compared with previously self-reported DS and national data. We applied latent class analysis (LCA) to identify classes of participants with similar COVID-19 related characteristics. The overall prevalence of significant DS was 53.3\%. By LCA posterior probabilities we identified three classes: (1) minimal impact of COVID-19 (54.1\%), (2) objective risk for COVID-19 (41.5\%), and (3) anxiety and economic stress caused by COVID-19 (4.4\%). Multivariate logistic regression showed that compared with those in class one, the odds to have significant DS were almost five times higher for those in class three. Our findings suggest high levels of depression among MSM and TGW in Mexico during the COVID-19 pandemic and highlight the need for the provision of targeted psychological interventions to minimize the impacts of COVID-19 on the mental health.

Keywords: COVID-19, mental health, depressive symptoms, Mexico, men who have sex with men

\section{INTRODUCTION}

On January 30, 2020, the World Health Organization (WHO) declared a public health emergency after identifying a cluster of unexplained cases of pneumonia in Wuhan, China, subsequently identified as COVID-19, caused by the novel coronavirus SARS-CoV-2 (1). In Mexico, as in the rest of the world, the spread of confirmed cases and deaths has increased dramatically, reaching 2,187,910 and 197,219, respectively, by March 21, 2021 (2). Since the beginning of the epidemic, the Mexican Ministry of Health $(\mathrm{MoH})$ has implemented a series of preventive measures including restricted mobility, sanitation and hygiene, and social distancing (including school closures, suspension of non-essential work activities, cancellation of massive events, and close of restaurants and bars). 
The COVID-19 pandemic and the uncertainty it creates in all aspects of life threaten people's physical and mental health. Elevated rates of anxiety, depression, posttraumatic stress disorder (PTSD), and harmful social behaviors (3) have been reported recently (4). A study carried out in 194 cities in China during the COVID-19 outbreak found that 54\% of respondents rated the psychological impact of the COVID-19 outbreak as moderate or severe. The prevalence of mild anxiety and depression among this population was 29 and $17 \%$, respectively (5). Another poll of 5,000 Chinese citizens showed PTSD symptoms among $21.5 \%$ of the participants, which resembles the prevalence of PTSD (28.9\%) and depression (31.2\%) experienced by quarantined citizens during the 2003 SARS outbreak (6). In the US, about a third of adults (32\%) reported in March 2020 that worry and stress related to COVID-19 harmed their mental health, $14 \%$ reported a more significant impact (7). Also, a recent literature review exploring the COVID-19 pandemic consequences on mental health revealed lower psychological well-being and higher scores of anxiety and depression in the general population, compared to before COVID-19 (8).

Evidence on the association between COVID-19 and mental health suggests that protective factors for stress, anxiety, and depression, include a high level of confidence in doctors, perceived survival likelihood, and low risk of contracting COVID-19 (9). Simultaneously, extreme fear, sleep deprivation, and living in severely afflicted areas are significant risk factors for COVID-19-related psychological distress (10). However, the available studies have been conducted mainly in China and other countries initially affected by the pandemic (7-11). The evidence remains limited in Latin American countries, where the current epicenter of the pandemic is, according to WHO. Furthermore, there is a severe lack of knowledge about the impact of COVID-19 on the mental health of highly vulnerable populations such as men who have sex with men (MSM) and transgender women (TGW).

In this paper, we used an online questionnaire to assess the prevalence of depressive symptoms (DS) among a sample of MSM and TGW during the 1st month of the COVID-19 outbreak in Mexico. We also document the association of DS to specific aspects linked to the COVID-19 pandemic, such as loss of a job, perceived risk of acquiring COVID-19, and change in sexual behavior due to COVID-19.

\section{METHODS}

\section{Study Overview and Population}

Between April 20th and 27th, 2020, we conducted an online survey about COVID-19 knowledge and attitudes among MSM and TGW. We sent an e-mail invitation to participants in an HIV pre-exposure prophylaxis (PrEP) demonstration project (ImPrEP) with more than 2,000 individuals recruited in three cities of Mexico: Mexico City, Guadalajara, and Puerto Vallarta. We also sent the e-mail invitation to $600 \mathrm{MSM}$ and TGW not enrolled in ImPrEP but contacted as part of the study's demand generation activities in venues frequently used by these populations to meet potential sex partners. Participants provided consent and contact information to be invited to participate in other studies. The survey instrument included questions on demographic characteristics, social support, general knowledge of COVID-19, the preventive measures to reduce the risk of contagion, risk factors and symptoms of COVID-19, the pandemic's impact on employment, and mental health indicators. Participants provided informed consent. The Institutional Review Board (IRB) of the National Institute of Public Health of Mexico reviewed and authorized the survey (IRB number: CI241-2020).

\section{Measures \\ Depressive Symptoms}

We used the 10-item version of the Center for Epidemiological Studies Depression Scale (CESD-10) to assess the presence of DS among survey participants. The CESD-10 measures the frequency of DS experienced in the past week, including a sense of loneliness, fear, depression, sleep disturbances, and feelings of helplessness and hopelessness (12). Ratings are based on a four-point response format from 0 (rarely or never) to 3 (mostly or always). Total scores range from 0 to 30 , and higher scores imply higher levels of DS. The CESD- 10 has demonstrated good internal reliability in the general population and has been used in past studies to assess DS among MSM and TGW PrEP users $(13,14)$ and the general Mexican population $(15,16)$. The CESD-10 provides an estimate of DS prevalence within a study population rather than a clinical diagnosis of depression. A cutoff score of ten or higher indicates the presence of significant DS (12).

We had access to data on DS before the onset of the COVID19 pandemic for ImPrEP participants who answered the SF36-questionnaire in $2019(n=108)$. We were able to compare the mental well-being before and during the outbreak for this subsample of individuals. The mental health module of the SF36 includes five questions about the frequency of depressive symptoms experienced in the past 4 weeks. Items include indicators of psychological distress and well-being. Ratings are based on a 6-point response format from 1 (all of the time) to 6 (never). Scores are calculated as the sum of every item (range from 5 to 30), and higher scores represent better health status. Raw scores are then transformed to a scale from 0 to 100 . We used a cut-off of 50 or lower in the SF-36 score to indicate the presence of significant DS (17).

To include an additional reference measure of DS, we also analyzed data from the 2018 wave of the National Survey of Health and Nutrition (ENSANUT 2018). The ENSANUT 2018 is a probabilistic representative sample of the Mexican population in all 32 states of Mexico. The ENSANUT 2018 assessed the presence of DS among respondents with the CESD-7, which is a shortened version of the CESD, which includes seven items whose ability to differentiate people with significant DS has been previously documented in the Mexican population (18). Additional details on the methodological design of the ENSANUT 2018 are reported elsewhere (19).

\section{Demographics}

We collected demographic characteristics of participants at the time of the survey, such as educational level (university degree or 
higher vs. less than university), age, gender, and state of residence (those who live in Mexico City vs. those living in other states of Mexico). We also assessed the perceived level of social support (having family or friends who can lend money if necessary and having family or friends who can take them to the hospital if sick). We created a categorical variable that indicates no social support $(=0)$, at least one type of social support $(=1)$, or both types of support $(=2)$.

\section{Covid-19 Related Variables}

We explored the effect and risk factors for COVID-19 in different aspects: loss of job because COVID-19 (yes/no), perceived risk of acquiring COVID-19 (not at risk/some risk/high risk), having at least one diagnosed risk factor for severe COVID-19 disease (hypertension, asthma, diabetes, obesity, tuberculosis, or cancer), and potential close contact with someone who has been tested positive for COVID-19 (yes/no). Because of high sexual activity reported during ImPrEP follow-up visits, we explored whether participants reduced their number of sexual partners due to COVID-19 (yes/no). We also explored the number and type of sexual partners (steady/occasional/transactional) in the last 2 weeks, and the use of dating apps.

\section{Analytical Approach}

We explored the distribution of demographics, social support, job loss, and risk of acquiring COVID-19 among those with and without significant DS. We assessed statistical differences using Chi-squared tests. We also compared the prevalence of DS in our sample with that in Mexico's general population (19).

We used latent class analysis (LCA) to identify the number of patterns (i.e., classes) of COVID-19 related variables. LCA is a person-centered approach for identifying common experiences across individuals, in contrast with variable-centered approaches that identify common relationships among variables
(20). Compared to other methodologies, LCA offers the opportunity to assess specific combinations of multiple risk factors simultaneously. It uses observed variables to identify common combinations or patterns of experiences that represent population subtypes.

We fitted multiple LCA models using the COVID-19 related variables previously described. We identified latent classes by estimating models with two to seven classes. We selected the best-fitting model based on account fit indices, including the Bayesian Information Criterion (BIC) and the Akaike Information Criterion (AIC) (20). We then estimated posterior probabilities and assigned individuals to the class for which the posterior probability was the highest (i.e., for which they had the closest fit). Following class identification, we estimated logistic regression models to assess the association between the presence of CESD-10 DS and the class assigned to each individual controlling for sociodemographic characteristics.

DS indicate psychological distress that might amount to a fullblown depressive disorder. At the same time, a certain level of DS can be a normal response to stressful circumstances. Thus, the association between DS and COVID-19-related variables might be more robust for DS scores in the middle range, while extremely high scores could indicate psychopathology beyond the stressrelated response. To assess whether the association between DS and COVID-19 related variables could be different in different points of the distribution of the CESD-10 score, we used quantile regressions and estimated coefficients at the mean, and Q25, Q50, Q75, and Q90. All the analyses were performed in Stata 15 (21).

\section{RESULTS}

We invited 3,049 individuals to answer the online survey. The response rate was 29\% (881 participants), and 595 MSM or TGW

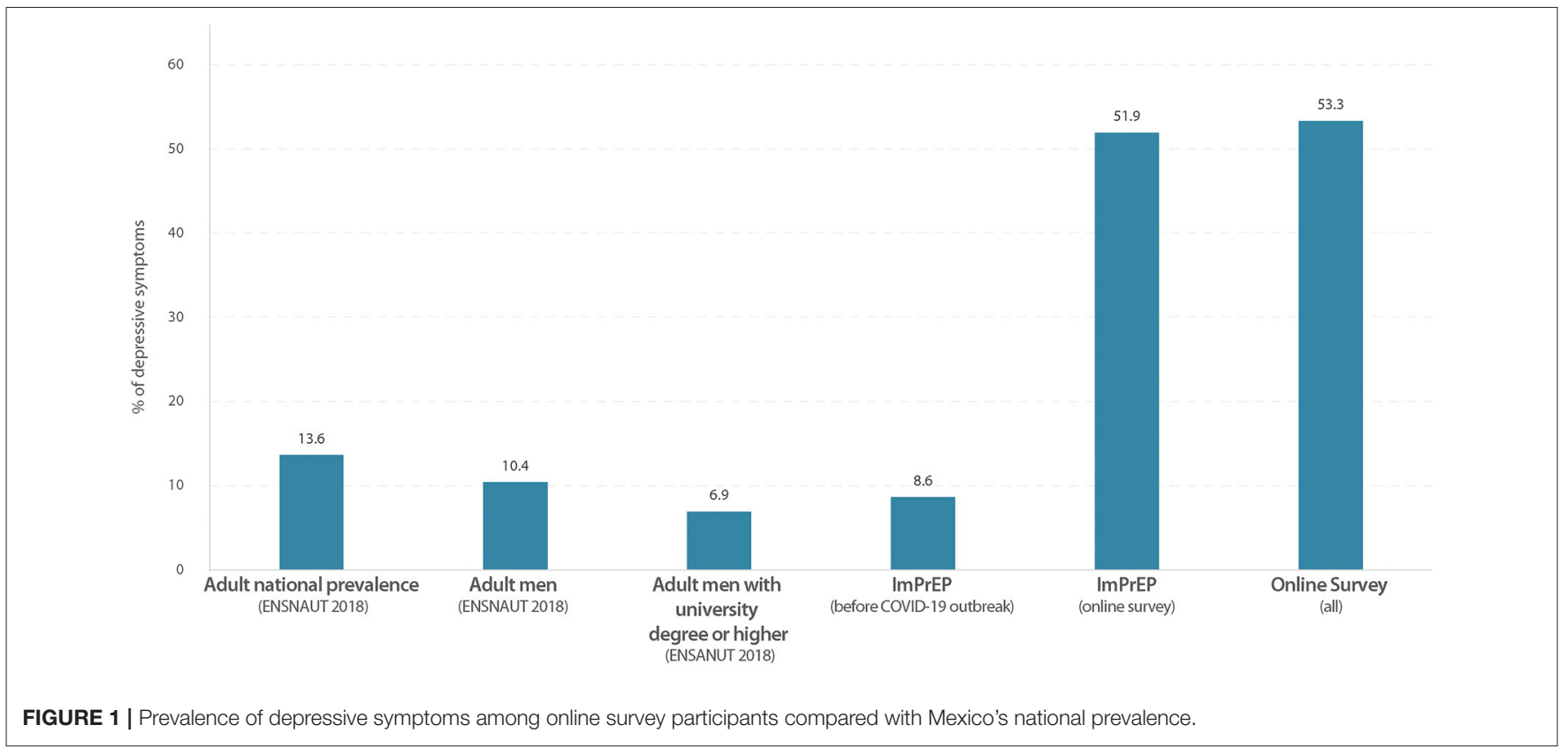


completed the online survey (67\% of respondents). Seventyseven percent of completed surveys corresponded to enrollees in the ImPrEP study. The overall prevalence of DS was 53\%, $83 \%$ reported schooling levels of university or higher, $53 \%$ were $28-36$

TABLE 1 | Demographic characteristics of participants with CESD-10 significant depressive symptoms $(n=317)$ and without significant depressive symptoms $(n=278)$.

\begin{tabular}{lcccc}
\hline Variable & No DS & DS & Total & $P$-value \\
$n(\%)$ & $278(46.7)$ & $317(53.3)$ & $595(100.0)$ & \\
\hline
\end{tabular}

\begin{tabular}{|c|c|c|c|c|}
\hline \multicolumn{5}{|l|}{ DEMOGRAPHICS } \\
\hline \multicolumn{5}{|l|}{ Education } \\
\hline Less than university & 39 (38.2) & $63(61.8)$ & $102(17.1)$ & \multirow[t]{2}{*}{0.059} \\
\hline $\begin{array}{l}\text { University degree of } \\
\text { higher }\end{array}$ & $239(48.5)$ & $254(51.5)$ & 493 (82.9) & \\
\hline \multicolumn{5}{|l|}{ Age } \\
\hline 18-27 years & $54(36.0)$ & $96(64.0)$ & $150(25.2)$ & \multirow[t]{3}{*}{0.002} \\
\hline 28-36 years & $150(47.6)$ & $165(52.4)$ & $315(52.9)$ & \\
\hline$>36$ years & $74(56.9)$ & $56(43.1)$ & $130(21.8)$ & \\
\hline \multicolumn{5}{|l|}{ State of residence } \\
\hline Lives in Mexico City & $186(43.1)$ & $246(56.9)$ & $432(72.6)$ & \multirow[t]{2}{*}{0.004} \\
\hline $\begin{array}{l}\text { Lives in other state } \\
\text { of Mexico }\end{array}$ & $92(56.4)$ & $71(43.6)$ & $163(27.4)$ & \\
\hline \multicolumn{5}{|l|}{ Social support } \\
\hline Null social support & $22(32.4)$ & $46(57.6)$ & $68(11.4)$ & \multirow[t]{3}{*}{0.030} \\
\hline Some social support & $72(45.9)$ & $85(54.1)$ & $157(26.4)$ & \\
\hline High social support & $184(49.7)$ & $186(50.3)$ & $370(62.2)$ & \\
\hline \multicolumn{5}{|l|}{ Gender } \\
\hline Male & $273(47.2)$ & $305(52.7)$ & $578(97.1)$ & \multirow[t]{2}{*}{0.147} \\
\hline Transgender women & $5(29.4)$ & $12(70.6)$ & $17(2.9)$ & \\
\hline \multicolumn{5}{|c|}{ Enrolled in ImPrEP study } \\
\hline Enrolled & $234(48.2)$ & $252(51.9)$ & $486(81.7)$ & \multirow[t]{2}{*}{0.141} \\
\hline Not enrolled & $44(40.4)$ & $65(59.6)$ & $109(18.3)$ & \\
\hline \multicolumn{5}{|c|}{ COVID-19 RELATED VARIABLES } \\
\hline \multicolumn{5}{|c|}{ Lost job because of COVID-19 } \\
\hline Yes & $55(38.7)$ & $87(61.3)$ & $142(23.9)$ & \multirow[t]{2}{*}{0.029} \\
\hline No & $223(49.2)$ & $230(50.8)$ & $453(76.1)$ & \\
\hline \multicolumn{5}{|c|}{ Perceived risk of acquiring COVID-19 } \\
\hline Null risk & $46(59.7)$ & $31(40.3)$ & $77(12.9)$ & \multirow[t]{3}{*}{$<0.001$} \\
\hline Some risk & $179(50.1)$ & $178(49.9)$ & $357(60.0)$ & \\
\hline High risk & $53(32.9)$ & $108(67.1)$ & $161(27.1)$ & \\
\hline \multicolumn{5}{|c|}{ Has at least one medical risk factor for severe COVID-19 disease } \\
\hline Yes & $99(38.8)$ & $156(61.2)$ & $255(42.9)$ & \multirow[t]{2}{*}{0.001} \\
\hline No & $179(52.6)$ & $161(47.4)$ & $340(57.1)$ & \\
\hline \multicolumn{5}{|c|}{ Knows someone with COVID-19 } \\
\hline Yes & $63(36.8)$ & $108(63.2)$ & $171(28.7)$ & \multirow[t]{2}{*}{0.002} \\
\hline No & $215(50.7)$ & $209(49.3)$ & $424(71.3)$ & \\
\hline \multicolumn{5}{|c|}{ Had contact with someone with COVID-19 } \\
\hline Yes & $7(41.2)$ & $10(58.8)$ & $17(2.86)$ & \multirow[t]{2}{*}{0.642} \\
\hline No & $271(46.9)$ & $307(53.1)$ & $578(97.1)$ & \\
\hline \multicolumn{5}{|c|}{ Decreased sexual partners because COVID-19 } \\
\hline Yes & $208(46.4)$ & $240(53.6)$ & $448(75.3)$ & \multirow[t]{2}{*}{0.802} \\
\hline No & $70(47.6)$ & 77 (52.4) & $147(24.7)$ & \\
\hline
\end{tabular}

years old, $72 \%$ of the respondents lived in Mexico City, and 3\% were TGW.

We compared the demographic characteristics of the ImPrEP participants with those not enrolled in ImPrEP. The only statistical difference we found was a higher proportion of enrolees living in Mexico City (Supplementary Table 1).

In Figure 1, we compare the prevalence of significant DS among study participants with Mexico's national prevalence and men's national prevalence, according to ENSANUT 2018. The prevalence in the Mexican adult population was $13.6 \%, 10.4 \%$ among men, and $6.9 \%$ among men with a university degree or higher. Significant DS prevalence during the COVID-19 lockdown was six times higher among those enrolled in the ImPrEP study than before the pandemic (51.9 vs. $8.6 \%$ ).

We explored differences in the distribution of demographic and COVID-19-related variables among participants, stratifying by the presence of significant DS (Table 1). We observed higher rates of DS among the youngest (36 years or younger) and Mexico City dwellers. Among participants without social support, 57.6\% had significant DS, compared with $50.3 \%$ in the group with high social support. The prevalence of significant DS was $61.3 \%$ among participants who lost their jobs because of COVID-19, compared to $50.8 \%$ if they did not lose their job. Significant DS were also more frequent among those who considered themselves at high risk of acquiring COVID-19 (67.1\%), with at least one medical risk factor for severe stages of COVID$19(61.2 \%)$, and those who know someone diagnosed with COVID-19 (63.2\%).

\section{Latent Class Analysis}

Following the LCA estimation, we summarized our data using a three-class model (Supplementary Table 5). Based on the itemspecific response probabilities, latent class labels were:

1. Minimal impact of COVID-19-54\%,

2. Objective risk of COVID-19-41\%, and

3. Anxiety and economic stress caused by COVID-19-4\%.

Figure 2 displays the results of the latent class analysis. The attribute of class one is a minimal impact of the pandemicdefined by $<25 \%$ probability of experience in any indicator of risk or negative effect of COVID-19. Class two is characterized by those objectively at risk for COVID-19 severe disease, with $99 \%$ of participants in this group reporting at least one objectively measured risk factor. Class three's feature is anxiety and economic stress caused by COVID-19. It includes participants who lost their jobs due to COVID-19 (53\%), knew someone with COVID-19 (99\%), perceived high risk of acquiring COVID-19 (74\%) or had contact with someone diagnosed with COVID-19 (52\%).

The prevalence of significant DS was 45,60 , and $80 \%$ for class one, two, and three, respectively (Figure 3 ). Besides education and state of residence, we did not observed differences in the distribution of demographic characteristics among classes. Regarding sexual behavior, those in class three reported less transactional sex compared with those in classes one and two (Supplementary Table 2). 


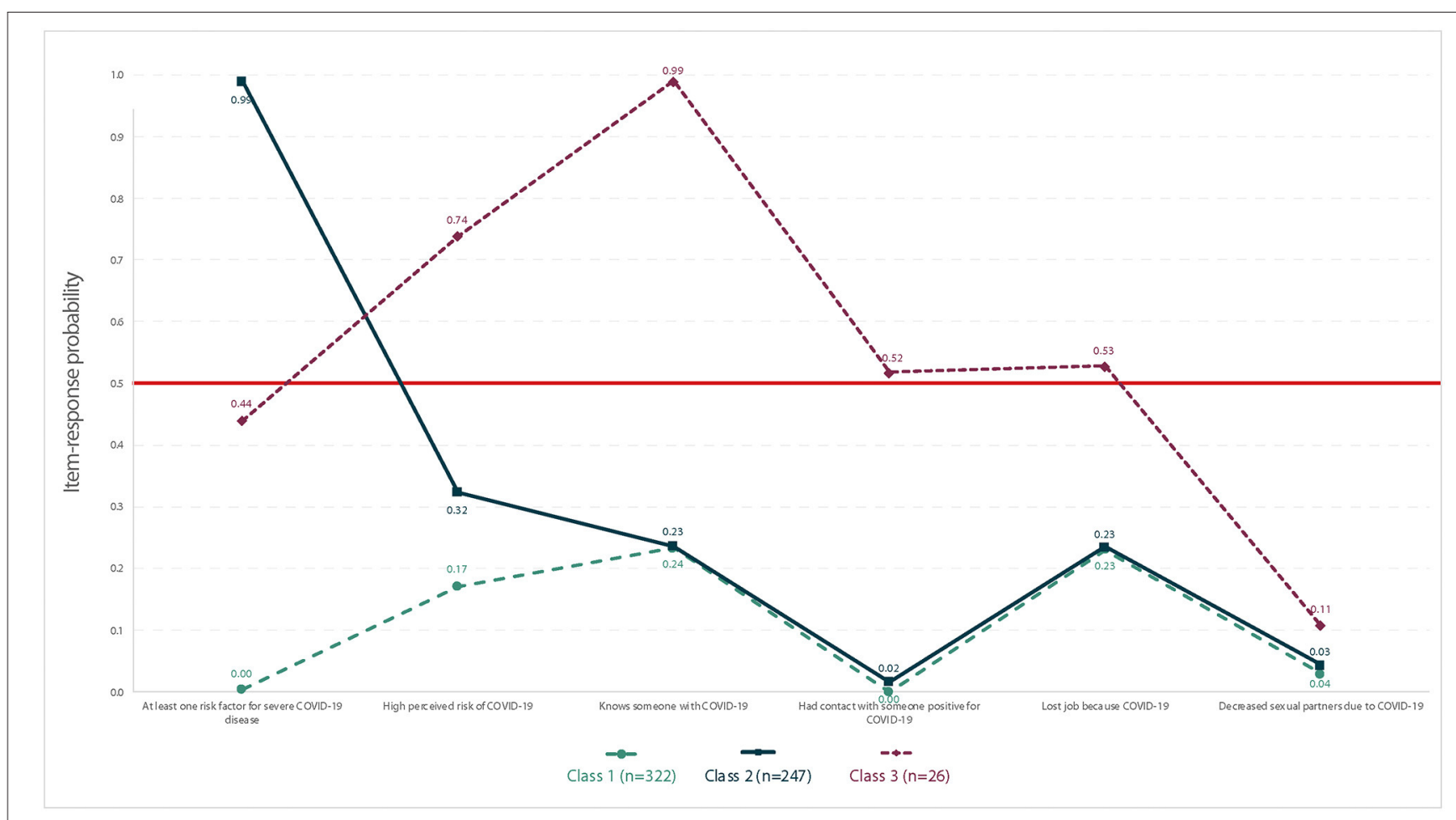

FIGURE 2 | Latent class analysis item-response for the three-class model of MSM and TGW ( $n=595)$.

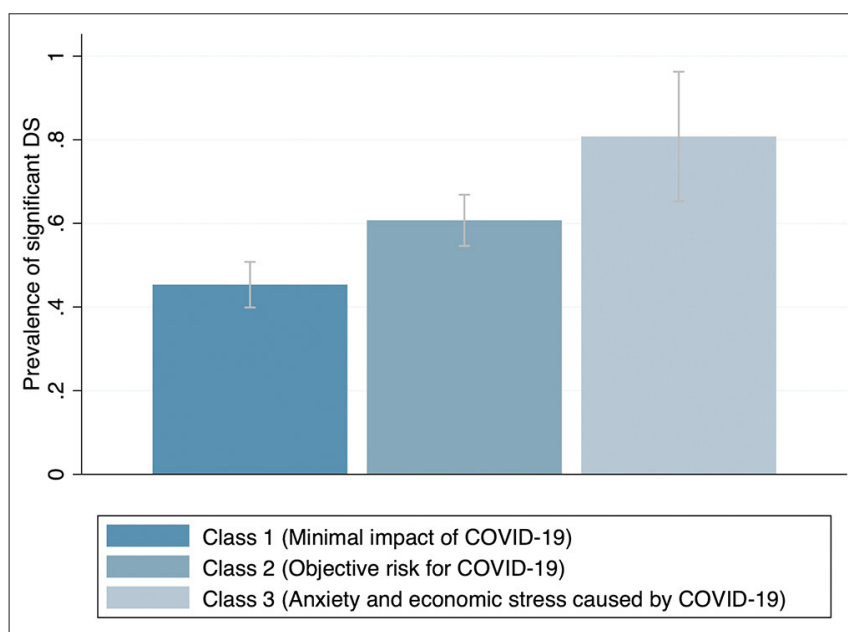

FIGURE 3 | Prevalence of significant DS by COVID-19 effect class.

In logistic regression models, latent class membership was associated with significant DS (Table 2, model 1). Compared with participants in class 1 , those at risk for COVID-19 (class 2) were nearly two times more likely to have significant DS (OR 1.86, 95\% CI 1.33-2.61); and those in class 3 were more than five times more likely to have significant DS (OR 5.06, 95\% CI 1.86-13.76). The statistical significance and magnitude of these correlations were consistent after controlling for demographic characteristics (Table 2, model 2).

\section{Quantile Regression analysis}

In Supplementary Table 3, we present the results of the quantile regression models to assess whether COVID-19 had a differential influence on DS across the distribution of the CESD-10 score. Column 1 shows the coefficients from the mean CESD-10 score, followed by the coefficients in the $25,50,75$, and 90 quantiles of the distribution. Job loss because of COVID-19, higher perception of risk, and at least one medical risk factor for severe COVID-19 disease, were positively associated with the CESD-10 score in the 10, 25, 50, and 75 quantiles. However, the variables were not associated with DS among the most severely depressed participants (Q90), except for knowing someone diagnosed with COVID-19.

\section{DISCUSSION}

Our study aimed to assess the prevalence of significant depressive symptoms and their association with the COVID-19 pandemic among a sample of MSM and TGW in Mexico.

Significant DS were highly prevalent in our sample (53.3\%), nearly seven times higher than men with a university degree or higher in ENSANUT 2018. Population-based mental health surveys have found consistently higher rates of major depression, anxiety, substance abuse, sexual and physical mistreatment, and suicidal behaviors in individuals disclosing same-sex sexual behavior or identifying as gay $(22,23)$. 
TABLE 2 | Odds ratios from logistic regression models identifying associations of latent class assignment by posterior probability with significant depressive symptoms.

\begin{tabular}{|c|c|c|}
\hline \multirow[b]{2}{*}{ Variables } & \multicolumn{2}{|c|}{ Model } \\
\hline & 1 & 2 \\
\hline \multicolumn{3}{|l|}{ Class of COVID-19 effects } \\
\hline Class 1 (minimal impact of COVID-19) & Ref & Ref \\
\hline \multirow[t]{2}{*}{ Class 2 (objective risk for COVID-19) } & $1.86^{\star \star \star}$ & $1.88^{\star \star \star}$ \\
\hline & $(1.33-2.61)$ & $(1.32-2.66)$ \\
\hline \multirow[t]{2}{*}{ Class 3 (economic stress caused by COVID-19) } & $5.06^{\star \star \star}$ & $4.98^{\star \star \star}$ \\
\hline & $(1.86-13.76)$ & $(1.79-13.83)$ \\
\hline \multicolumn{3}{|l|}{ Demographics } \\
\hline \multirow[t]{2}{*}{ Education level } & & 0.84 \\
\hline & & $(0.51-1.36)$ \\
\hline$\geq 36$ years & & Ref \\
\hline \multirow[t]{2}{*}{$18-27$ years } & & $2.63^{\star \star \star}$ \\
\hline & & $(1.57-4.43)$ \\
\hline \multirow[t]{2}{*}{ 28-36 years } & & $1.58^{\star \star}$ \\
\hline & & $(1.03-2.43)$ \\
\hline \multirow[t]{2}{*}{ Lives in Mexico City ( 1 = yes) } & & $1.67^{\star \star \star}$ \\
\hline & & $(1.14-2.45)$ \\
\hline Null social support & & Ref \\
\hline \multirow[t]{2}{*}{ Some social support } & & $0.56^{\star}$ \\
\hline & & $(0.29-1.04)$ \\
\hline \multirow[t]{2}{*}{ High social support } & & $0.48^{\star \star}$ \\
\hline & & $(0.27-0.85)$ \\
\hline \multirow[t]{2}{*}{ Gender ( 1 = male) } & & 0.54 \\
\hline & & $(0.18-1.65)$ \\
\hline \multirow[t]{2}{*}{ ImPrEP participant ( 1 = yes) } & & 0.74 \\
\hline & & $(0.47-1.15)$ \\
\hline \multirow[t]{2}{*}{ Constant } & $0.83^{\star}$ & 1.76 \\
\hline & $(0.666-1.033)$ & $(0.49-6.33)$ \\
\hline Observations & 595 & 595 \\
\hline
\end{tabular}

95\% Cl in parentheses; ${ }^{* \star *} p<0.01,{ }^{* *} p<0.05,{ }^{*} p<0.1$.

However, our results support the hypothesis that the COVID19 pandemic has increased the prevalence of DS substantially. DS were almost six times more prevalent in our study than in the baseline measurement in the same populations before the COVID-19 outbreak (51.9 vs. 8.6\%). The prevalence of DS in our study was almost twice as high as the iPrEX OLE trial (51.9 vs. 28\%) among MSM on PrEP in 2016 (14).

Furthermore, the prevalence of SD among the group of individuals in class 1 (minimally affected by COVID-19), was the lowest in our study $-45.3 \%$, compared with $60.7 \%$ in class 2 (objective risk), and $80.7 \%$ in class 3 (anxiety and economic stress). Our multivariate models showed that compared with those in class 1, participants in class 3 were almost five times more likely to present significant DS.

Our findings are consistent with previous studies showing that stressful situations like job loss are associated with an increased risk of DS and clinical depression (24). Job loss is a well-known risk factor for mental health conditions; however, our results add to recent literature documenting the high self-perceived risk of COVID-19 and contact with someone diagnosed with COVID19 as risk factors. A recent study assessed the psychological effects of COVID-19 in the Chinese population and found that those with close contact with an individual with confirmed COVID-19 and those with a higher perceived risk of acquiring COVID-19 had a higher likelihood for depression (5).

We also observed a higher prevalence of significant DS among participants living in Mexico City, the state with the highest number of COVID-19 cases and deaths. Previous studies have shown that the prevalence of PTSD symptoms is higher in most affected communities by COVID-19. One study in China showed that 1 month after the outbreak, PTSD symptoms were present in $4.6 \%$ of mainland China population against $18.4 \%$ in provinces with a higher number of COVID-19 cases (25). In our study, DS were significantly more prevalent among people reporting less social support, consistent with previous studies showing that higher social support and better social connection quality lower the risk of DS (26). A study among young adults in the US found that high levels of loneliness were associated with clinical levels of depression, anxiety, and PTSD symptoms. The same study also found that having social support from family and friends was a significant predictor of low levels of depression and PTSD (27).

COVID-19-related variables were not significantly associated with the CESD-10 score in the higher quantile of the distribution (except for knowing someone diagnosed with COVID-19). Simultaneously, demographic characteristics such as age and state of residence were significant predictors of this quantile score, which might be associated with a specific profile of MSM and TGW, who suffered from severe depression before the outbreak.

One important implication of the high prevalence of DS is the potential impact of depression on other health outcomes of our participants. Mental health conditions, including depression, are known barriers to health care engagement and daily medication adherence. One study conducted among PrEP users in East Africa found that depressive symptoms were significantly associated with lower rates of PrEP adherence among participants (28).

Also, DS are related to increased HIV risk behaviors (multiple sexual partners, condomless sex), poor social support, and substance abuse (29). Among adults living with HIV, those with DS were 55\% less likely to achieve optimal daily antiretroviral therapy (ART) adherence (30). Since MSM and TGW carry a disproportionate burden of the HIV epidemic (31), proper adherence to PrEP and other HIV prevention strategies is crucial to reduce the burden of HIV among these populations.

Our study is one of the firsts addressing the prevalence of DS and the association with COVID-19 related variables among HIV high-risk populations in Latin America. Although several studies have documented increases in the prevalence of depression, anxiety, and PTSD during the COVID-19 outbreak and lockdown, most of them were conducted in Asia and Europe and focused on the general population or health care workers (8). Because of that, the generalization of their results is limited for contexts like Latin America and to populations with very particular characteristics like MSM and TGW. 
Our findings should be interpreted in light of several limitations of the study. First, baseline measurement of DS among the ImPrEP participants before social distancing measures is based on the SF-36 scale. However, previous studies have suggested that the SF-36 and CESD-10 depression scales measure similar constructs, and a strong correlation between both scores has been documented (32). Second, we did not collect information on how COVID-19 impacted participants' social support group. Third, those with complete information on all the variables included in our study were significantly more educated and younger than those with incomplete information (Supplementary Table 4). It is difficult to assess the direction of the bias introduced by this selection process. When comparing the ImPrEP participants' characteristics in our online survey with the ImPrEP's full sample, we observed that participants living in Mexico City are overrepresented (64\% ImPrEP sample vs. 73\% online survey). Since Mexico City is the most affected state in the country by COVID-19, this can explain the high prevalence of DS among the sample. Finally, our findings cannot be generalized because of the particular profile of our participants--highly educated compared with the general population in Mexico.

As the COVID-19 epidemic continues to spread, we hope our findings will help inform strategies to minimize the impacts of COVID-19 on the mental health of MSM in Mexico and other places affected by the epidemic. PrEP and other HIV prevention programs across the globe will probably need to address this health problem among their users explicitly and include psychological interventions in their design.

\section{CONCLUSIONS}

During the 1st month of the COVID-19 outbreak in Mexico, more than half of the MSM and TGW participants in this online survey had significant DS. Our findings emphasize the need for targeted psychological interventions for populations affected by COVID-19, particularly for individuals already at high risk for poor mental health outcomes. Mechanisms to better monitor and diagnose mental health disorders and improve access to psychological interventions to diminish or prevent future psychiatric morbidity among PrEP and non-PrEP users are necessary. Finally, additional research is needed to assess the potential impact of poor mental health on other outcomes, such as PrEP adherence, the adoption of HIV risk behaviors, and adherence to COVID-19 preventive measures.

\section{REFERENCES}

1. World Health Organization (WHO). Statement on the Meeting of the International Health Regulations (2005) Emergency Committee Regarding the Outbreak of Novel Coronavirus (2019-nCoV). (2020). Available online at: https://www.who.int/news/item/23-01-2020-statement-on-the-meetingof-the-international-health-regulations-(2005)-emergency-committeeregarding-the-outbreak-of-novel-coronavirus-(2019-ncov) (accessed July 15, 2020).

2. World Health Organization (WHO). Coronavirus Disease (COVID-19) Situation Report - 185. (2020). Available online at: https://www.who.int/docs/ default-source/coronaviruse/situation-reports/20200723-covid-19-sitrep185.pdf?sfvrsn=9395b7bf_2 (accessed July 24, 2020)

\section{DATA AVAILABILITY STATEMENT}

The raw data supporting the conclusions of this article will be made available by the authors, without undue reservation.

\section{ETHICS STATEMENT}

The study involving human participants was reviewed and approved by the Ethics Committee of the National Institute of Public Health (IRB number: CI-241-2020). Participants provided their written informed consent to participate in the study.

\section{AUTHOR CONTRIBUTIONS}

DC-G lead the analysis and wrote the first draft of the paper. HV, JG-C, AM-D, and IH-I collaborated in the design of instruments and reviewed the paper. JA conducted analyses and review the paper. IB reviewed the final version of the paper and contributed to interpretation of results. SB-A designed the original study and supervised the development of the manuscript. All authors contributed to the article and approved the submitted version.

\section{FUNDING}

This work was funded by UNITAID and the National Institute of Public Health of Mexico.

\section{ACKNOWLEDGMENTS}

We thank ImPrEP study participants, staff, and implementing sites: Clinica Especializada Condesa, Fundación Unidos por un México Vivo A.C., Comité Humanitario de Esfuerzo Compartido Contra El SIDA (CHECCOS) A.C., and SETAC. In particular, we would like to thank Juan Pablo Osuna Noriega, Israel Macias, Jehovani Tena, Andrea Gonzáles, Jorge Bernal, Rodrigo Moheno, Gerardo Vizcaino, Víctor Dante Galicia, Alfredo Soria, and Francisco Arjona for their work co-ordinating the implementation sites.

\section{SUPPLEMENTARY MATERIAL}

The Supplementary Material for this article can be found online at: https://www.frontiersin.org/articles/10.3389/fpubh. 2021.598921/full\#supplementary-material

3. Shigemura J, Ursano RJ, Morganstein JC, Kurosawa M, Benedek DM. Public responses to the novel 2019 coronavirus (2019-nCoV) in Japan: mental health consequences and target populations. Psychiatry Clin Neurosci. (2020) 74:281. doi: 10.1111/pcn. 12988

4. Bao Y, Sun Y, Meng S, Shi J, Lu L. 2019-nCoV epidemic: address mental health care to empower society. Lancet. (2020) 395:e37-8. doi: 10.1016/S0140-6736(20)30309-3

5. Wang C, Pan R, Wan X, Tan Y, Xu L, Ho CS, et al. Immediate psychological responses and associated factors during the initial stage of the 2019 coronavirus disease (COVID-19) epidemic among the general population in China. Int J Environ Res Public Health. (2020) 17:1729. doi: $10.3390 /$ ijerph17051729 
6. Hawryluck L, Gold WL, Robinson S, Pogorski S, Galea S, Styra R. SARS control and psychological effects of quarantine, Toronto, Canada. Emerg Infect Dis. (2004) 10:1206. doi: 10.3201/eid1007.030703

7. Hamel L, Lopes L, Muñaña C, Kates J, Michaund J, Brodie M. KFF Coronavirus Poll: March 2020. (2020). Available online at: https://www.kff. org/coronavirus-covid-19/poll-finding/kff-coronavirus-poll-march-2020/ (accessed July 24, 2020).

8. Vindegaard N, Eriksen Benros M. COVID-19 pandemic and mental health consequences: systematic review of the current evidence. Brain Behav Immun. (2020) 89:531-42. doi: 10.1016/j.bbi.2020.05.048

9. Wang C, Pan R, Wan X, Tan Y, Xu L, McIntyre RS, et al. A longitudinal study on the mental health of general population during the COVID-19 epidemic in China. Brain Behav Immun. (2020) 87:40-8. doi: 10.1016/j.bbi.2020.04.028

10. Tang W, Hu T, Hu B, Jin C, Wang G, Xie C, et al. Prevalence and correlates of PTSD and depressive symptoms one month after the outbreak of the COVID19 epidemic in a sample of home-quarantined Chinese university students. $J$ Affect Disord. (2020) 274:1-7. doi: 10.1016/j.jad.2020.05.009

11. González-Sanguino C, Ausín B, Castellanos MÁ, Saiz J, López-Gómez A, Ugidos C, et al. Mental health consequences during the initial stage of the 2020 coronavirus pandemic (COVID-19) in Spain. Brain Behav Immun. (2020) 87:172-6. doi: 10.1016/j.bbi.2020.05.040

12. Andresen EM, Malmgren JA, Carter WB, Patrick DL. Screening for depression in well older adults: Evaluation of a short form of the CES-D. Am J Prev Med. (1994) 10:77-84.

13. Defechereux PA, Mehrotra M, Liu AY, McMahan VM, Glidden DV, Mayer KH, et al. Depression and oral FTC/TDF pre-exposure prophylaxis (PrEP) among men and transgender women who have sex with men (MSM/TGW). AIDS Behav. (2016) 20:1478-88. doi: 10.1007/s10461-015-1082-2

14. Mehrotra ML, Glidden DV, McMahan V, Amico KR, Hosek S, Defechereux $\mathrm{P}$, et al. The effect of depressive symptoms on adherence to daily oral PrEP in men who have sex with men and transgender women: a marginal structural model analysis of the iPrEx OLE study. AIDS Behav. (2016) 20:1527-34. doi: 10.1007/s10461-016-1415-9

15. Chapela IB, de Snyder NS. Características psicométricas de la Escala Center for Epidemiological Studies-depression (CES-D), versiones de 20 y 10 reactivos, en mujeres de una zona rural mexicana. Salud Ment. (2009) 32:299-307.

16. Salinas-Rodríguez A, Manrique-Espinoza B, Acosta-Castillo GI, FrancoNúñez A, Rosas-Carrasco Ó, Gutiérrez-Robledo LM, et al. Validation of a cutoff point for the short version of the depression scale of the center for epidemiologic studies in older Mexican adults. Salud Publica Mex. (2014) 56:279-85. doi: 10.21149/spm.v55i3.7209

17. Ware JE. SF-36 health survey update. Spine. (2000) 25:3130-9. doi: 10.1097/00007632-200012150-00008

18. Salinas-Rodríguez A, Manrique-Espinoza B, Acosta-Castillo I, TéllezRojo MM, Franco-Núñez LA, Gutiérrez-Robledo LM, et al. Validación de un punto de corte para la escala de depresión del centro de estudios epidemiológicos, versión abreviada (cesd-7). Salud Publica Mex. (2013) 55:267-74. doi: 10.21149/spm.v56i3.7346

19. Romero-Martínez M, Shamah-Levy T, Vielma-Orozco E, Heredia-Hernández O, Mojica-Cuevas J, Cuevas-Nasu L, et al. Encuesta Nacional de Salud y Nutrición (Ensanut 2018): metodología y perspectivas. Salud Publica Mex. (2019) 61:917-23. doi: 10.21149/11095

20. Lanza ST, Rhoades BL, Nix RL, Greenberg MT. Modeling the interplay of multilevel risk factors for future academic and behavior problems: a person-centered approach. Dev Psychopathol. (2010) 22:313. doi: 10.1017/S0954579410000088

21. StataCorp. Stata Statistical Software: Release 15. College Station, TX: StataCorp LLC (2017).
22. Stall R, Mills TC, Williamson J, Hart T, Greenwood G, Paul J, et al. Association of co-occurring psychosocial health problems and increased vulnerability to HIV/AIDS among Urban men who have sex with men. Am J Public Health. (2003) 93:939-42. doi: 10.2105/ajph.93.6.939

23. Cochran SD, Mays VM. Lifetime prevalence of suicide symptoms and affective disorders among men reporting same-sex sexual partners: Results from NHANES III. Am J Public Health. (2000) 90:573. doi: 10.2105/ajph. 90.4.573

24. Kim TJ, von dem Knesebeck O. Perceived job insecurity, unemployment and depressive symptoms: a systematic review and meta-analysis of prospective observational studies. Int Arch Occup Environ Health. (2016) 89:56173. doi: 10.1007/s00420-015-1107-1

25. Liu N, Zhang F, Wei C, Jia Y, Shang Z, Sun L, et al. Prevalence and predictors of PTSS during COVID-19 outbreak in China hardest-hit areas: gender differences matter. Psychiatry Res. (2020) 287:112921. doi: 10.1016/j.psychres.2020.112921

26. Werner-Seidler A, Afzali MH, Chapman C, Sunderland M, Slade T. The relationship between social support networks and depression in the 2007 National Survey of Mental Health and Well-being. Soc Psychiatry Psychiatr Epidemiol. (2017) 52:1463-73. doi: 10.1007/s00127-0171440-7

27. Liu CH, Zhang E, Wong GTF, Hyun S, Hahm H “Chris.” Factors associated with depression, anxiety, et al.S. young adult mental health. Psychiatry Res. (2020) 290:113172. doi: 10.1016/j.psychres.2020.113172

28. Velloza J, Baeten JM, Haberer J, Ngure K, Irungu E, Mugo NR, et al. Effect of depression on adherence to oral PrEP amongmen and women in East Africa. J Acq Immune Deficiency Synd. (2018) 79:330. doi: 10.1097/QAI.0000000000001821

29. Lennon CA, Huedo-Medina TB, Gerwien DP, Johnson BT. A role for depression in sexual risk reduction for women? A meta-analysis of HIV prevention trials with depression outcomes. Soc. Sci. Med. (2012) 75:68898. doi: 10.1016/j.socscimed.2012.01.016

30. Mayston R, Kinyanda E, Chishinga N, Prince M, Patel V. Mental disorder and the outcome of HIV/AIDS in low-income and middleincome countries: a systematic review. Aids. (2012) 26:S117-35. doi: 10.1097/QAD.0b013e32835bde0f

31. Bautista-Arredondo S, Colchero MA, Romero M, Conde-Glez CJ, SosaRubí SG. Is the HIV epidemic stable among MSM in Mexico? HIV prevalence and risk behavior results from a nationally representative survey among men who have sex with men. PLoS ONE. (2013) 8:e72616. doi: 10.1371/journal.pone.0072616

32. Chin WY, Choi EPH, Chan KTY, Wong CKH. The psychometric properties of the center for epidemiologic studies depression scale in Chinese primary care patients: Factor structure, construct validity, reliability, sensitivity and responsiveness. PLOS ONE. (2015) 10:e0135131 doi: 10.1371/journal.pone.0135131

Conflict of Interest: The authors declare that the research was conducted in the absence of any commercial or financial relationships that could be construed as a potential conflict of interest.

Copyright (ㄷ 2021 Cerecero-Garcia, Vermandere, Bojorquez, Gómez-Castro, Arturo Sánchez-Ochoa, Martínez-Dávalos, Huerta-Icelo and Bautista-Arredondo. This is an open-access article distributed under the terms of the Creative Commons Attribution License (CC BY). The use, distribution or reproduction in other forums is permitted, provided the original author(s) and the copyright owner(s) are credited and that the original publication in this journal is cited, in accordance with accepted academic practice. No use, distribution or reproduction is permitted which does not comply with these terms. 